\title{
Vascular Complications after Surgery of Lumber Disc Herniation: about Two Cases and Rerview of the Litterature
}

\author{
Elfatemi B*, Bakkali T, Khloufi S, Sefiani Y, Lekehel B, Mesnaoui A, Ammar F, Bensaid Y
}

Vascular surgery department hospital Ibn Sina Rabat

DOI: $10.36347 /$ sasjs.2020.v06i03.011

| Received: 07.03.2020 | Accepted: 14.03.2020 | Published: 19.03.2020

*Corresponding author: Elfatemi Bouthainah

Abstract

Case Report

Two observations of vascular complications after surgery for lumbar posterior disc herniation are reported. The first of a retroperitoneal hematoma with lower limb ischemia on lesion of the primitive iliac artery treated surgically by transposition of the superficial femoral artery and replacement of the latter by an inverted long saphenous vein graft. And the second observation of an iliocaval fistula with predominantly right-sided heart failure treated by a femoral stent. Vascular complications of lumbar disc surgery are rare (about $0.04 \%$ of discectomies) but of a great severity. The lesions observed are very different on both anatomically and clinically sides. Their diagnosis is frequently unknown at the time of the operation and it is sometimes only after several years that they are discovered, especially for non-hemorrhagic forms: arteriovenous fistulas. The treatment is essentially surgical but recently endovascular treatment has been successfully performed several times.Through these two observations the circumstances of occurrence will be recalled, the different clinical forms and therapeutic procedures according to the way in which these complications will be then presented.

Keywords: Disc herniation - vascular complications - hemorrhage- arteriovenous fistula - endovascular treatment. Copyright @ 2020: This is an open-access article distributed under the terms of the Creative Commons Attribution license which permits unrestricted use, distribution, and reproduction in any medium for non-commercial use (NonCommercial, or CC-BY-NC) provided the original author and source are credited.

\section{INTRODUCTION}

Surgery of lumbar or lumbosacral disc herniations, first performed by Mixter and Barr in 1934 [1], has a reputation of being benign. André Sicard's series of 1,720 cases with a mortality rate of $1.7 \%$ and a complication rate of less than $2.5 \%$ [2].

Among the complications of disc surgery, vascular damage is probably the rarest. The polymorphism of clinical manifestations can be extremely variable depending on the type of trauma. The first case was described by Linton and White in 1945 [3], 11 years after the publication of Mixter and Barr's Princeps. However, these are probably the most serious complications, since the major series in the literature report a mortality rate of $8 \%$ [4] to $65 \%$ [5]. Treatment in the past was primarily surgical, but advances in endovascular techniques have replaced conventional surgery.

Two observations of two patients operated on for disc herniation whose seat, the clinical presentation and the therapeutic approach were completely different will be presented, showing the polymorphic nature of these complications.

\section{Clinical Case 1}

Mr. T. S., which is 21 years old, a great sportsman, followed for one year for lumbo-sciatica left rebellious to medical treatment, is operated in emergency in a hyperalgesic sciatic picture on a herniated disc L5-S1 objectified through the CT scan. The patient had benefited from a discectomy with laminectomy by a posterior way which proceeded normally. 24 hours after surgery, the patient presented a functional impotence shock of the left lower limb. The patient was ex-sanguinated, hypotensive, his abdomen was tender with impaction of the left iliac fossa, his left lower limb was ischemic with sensomotor paralysis. Abdominal echo scan performed at the patient's bedside showed a large retroperitoneal hematoma.

The diagnosis of a rupture of a large retroperitoneal vessel was set and surgery was decided on an emergency basis.

The approach was left retroperitoneal. Exploration found a huge retroperitoneal hematoma secondary to a puncture wound on the posterior aspect of the left common iliac artery with significant loss of substance. This wound was located 1.5 centimeters at the origin of the artery. The left primitive iliac vein was 
intact. After upstream and downstream control of the left primitive iliac artery, any attempt to simply suture the wound was impossible; for this reason the arterial segment was resected and replaced by an autologous arterial graft (taken from the right superficial femoral artery) interposed terminally. The continuity of the superficial femoral artery was ensured by an inverted long saphenous vein graft. Aponevrotomies of the anterolateral and posterior chambers were then performed.

The patient received 8 units of whole blood during the operation. The post-operative period was very disturbed, marked first by the appearance on the second day of necrosis of the muscles of the anteroexternal lodge with permeable vessels, which required surgical removal of the entire lodge.

A re-vascularization syndrome on the third day with very important biological disturbances appeared: urea at $4 \mathrm{~g} / \mathrm{l}$, creatinine at $90 \mathrm{mg} / \mathrm{l}$, kalemia at $7 \mathrm{mEq} / \mathrm{l}$. Nosocomial pneumopathy on the sixth day treated with antibiotics and artificial ventilation. Withdrawal from ventilation was not possible until day 14 . The resuscitation stay was 23 days. The patient's discharge was decided on the 35th day. Revised at 2 months and 6 months, the patient's examination is on the vascular side satisfactory, however he has retained stepping-type nervous disorders with instability of the left ankle for which rehabilitation sessions have been scheduled.

\section{Clinical Case 2}

Mrs. H.F, 54 years old, operated in 2004 for disc herniation L4-L5 in Casablanca for lumbar posterior edge herniation. The postoperative course was marked by the appearance of oedema of both lower limbs, progressively worsening dyspnea and signs of predominantly right heart failure: hepatomegaly, turgidity of the jugular veins as well as pericardial effusion treated with a decompressive cardiac surgery.

In view of the patient's altered general condition, a trans-thoracic ultrasound scan was performed, and revealed: hyper cardiac output, dilated inferior vena cava and significant tricuspid insufficiency + PAH. The right cavities were moderately dilated with reflux in the supra-hepatic veins.

An echo doppler scan of the lower limbs was performed, revealing the presence of an extremely large-flow iliocaval arteriovenous fistula between the right iliac artery and the inferior vena cava measured $2 \mathrm{~cm}$ wide, which was confirmed by an angioscanner exam (Figure-1). operation a cardiac echo endoscopic monitoring was set up. A mini approach of the right Scarpa allowing to put on the lake the common femoral artery.

During the approach, the arch of the long saphenous vein was extremely voluminous, more than one centimeter long, which is perfectly explainable in the context of venous hypertension linked to the fistula. We're mounting a leader under a brilliance amplifier.

Visualization of this absolutely massive fistula, no contrast material opacifies the iliac artery downstream of the fistula, all of the contrast material passes directly into this full-channel fistula in the vena cava (Figure-2).

This vena cava is very bulky, measuring about $4 \mathrm{~cm}$. Placement of the stent V12 ATRIUM diameter 12, length 40 and expansion of the stent with a balloon. The check shows a persistent leak, a second prosthesis is repositioned towards the ATRIUM V12 11-diameter iliac bifurcation after insertion, a very small late leak persists, it is re-blowed at a pressure of 12 Atm and the leak disappears completely (Figure-3). The postoperative effects were simple.

Postoperative RTT in October 2012: return to normal cardiac output at $5.21 / \mathrm{min}$, relative septal hypokinesia in a context of major correction of cardiac output and less dilated right heart chambers.

A follow-up angioscanner exam two years later shows definitive exclusion of the fistula with a reduction in the size of the inferior vena cava and suprahepatic veins, and no endoleak (Figure-4).

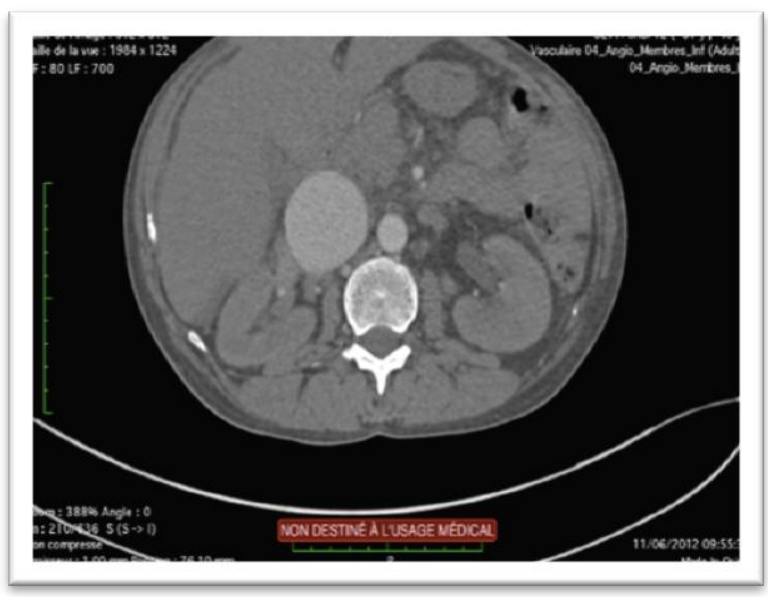

Fig-1: CT angiography of the abdominal aorta at arterial time showing the opacification of the inferior vena cava

The patient underwent surgery in September 2012 with a right iliac femoral stent graft. During the 


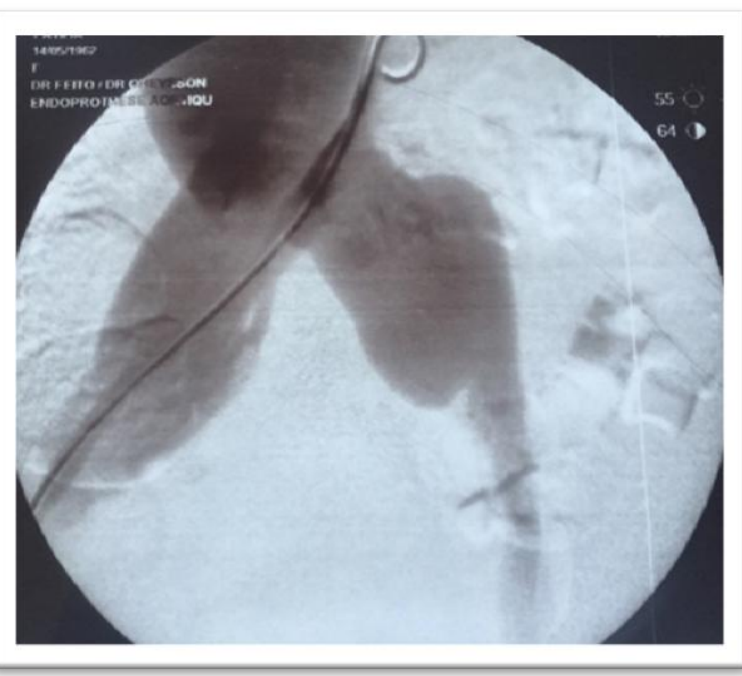

Fig-2: Per operative angiographic image showing the lack of opacification of the aorta and iliac artery due to the ilio-vascular arteriovenous shunt

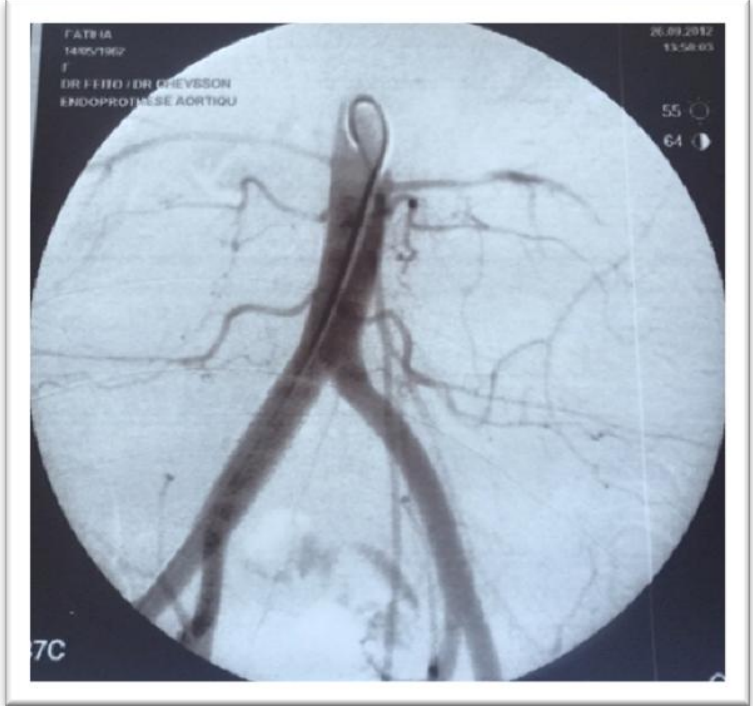

Fig-3: Definitive exclusion of the ilio cave fistula with satisfactory angiographic control

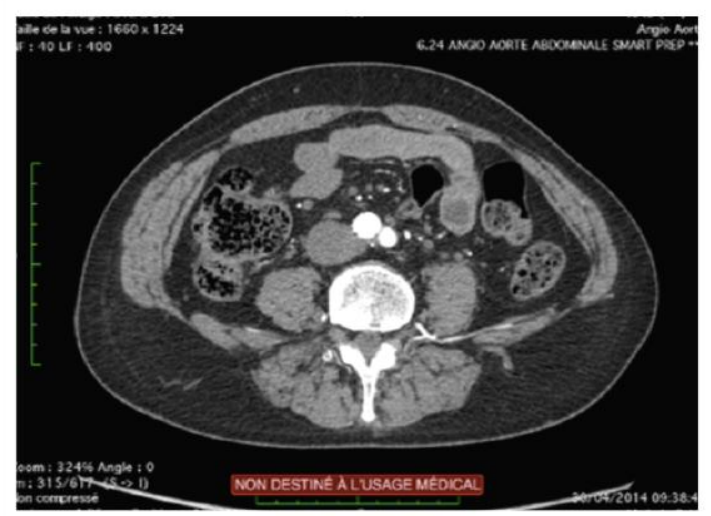

Fig-4: Two-year follow-up CT angiography: permeable stent with no endoleak

\section{DISCUSSION}

The frequency of vascular complications after disc herniation surgery by posterior lumbar approach is still unknown, but probably remains low in relation to the number of herniated discs operated on: for example, Wildförster [5], following a survey of members of the German Society of Neurosurgery, collected 31 cases of vascular injury out of 68,329 discectomies, i.e. a frequency of $0.045 \%$, and Papadoulas et al., [6] found a comparable frequency in their personal series of discectomies: one case out of 2590 operations, or $0.04 \%$.

The factors that favor the occurrence of this type of complication are essentially the close anatomical relationship between the lumbar spine and the iliac vessels as well as the aortic bifurcation, the position, the different approaches and the use of certain instruments (gouge forceps, rodents...).

Diagnosis of vascular injury during discectomy is difficult to set. Although trauma usually involves very large vessels, operative bleeding from the intervertebral space is very inconsistent. It was observed in only $28.3 \%$ of patients in the Jarstfer and Rich series [4] and was alarming in only $19.5 \%$ of these patients, while $71.7 \%$ of patients had no bleeding. The number of operation reports available shows that the interventions were performed without any problems. In cases of hemorrhage, it has been falsely attributed to bleeding from the epidural veins and its arrest after tamponade with hemostatic sponges has contributed to the misdiagnosis. This was stated during the intervention or during the first 24 hours in less than half of the cases: $47 \%$ in the DeSaussure series [7], 38\% in the Papadoulas et al. series [6]. However, for the latter authors, in the case of a wound isolated from a large vessel, early diagnosis was made in $93 \%$ of cases and only in the majority of cases. The hemorrhage, due to the ventral operating position, flows preferentially towards the retroperitoneal space, which explains the relative rarity of bleeding through the intervertebral space and the lack of knowledge of vascular damage during the operation. The other non-hemorrhagic forms are dominated by the occurrence of arteriovenous fistulas as in the case of the patient reported and false aneurysms of the iliac vessels.

Endovascular treatment has become the preferred treatment for these vascular lesions, except in the case of massive hemorrhage. In the latter case indeed, surgical treatment remains the rule. Micro-coil embolization has been successfully performed in a case of injury to the superior hemorrhoidal artery [8].

Difficult exposure of the abdomino-pelvic vessels and venous hyper-pressure explain why surgical repair of these lesions is associated with a high rate of bleeding and mortality, especially if performed in an unstable hemodynamic state $[16,17]$. 
Endovascular treatment is therefore a newer and less invasive alternative. It is based on the use of covered stents to close the communication while preserving arterial and venous permeability $[16,18,22]$. It can only be performed in cases of stable hemodynamic status and favorable anatomical conditions, and is also indicated in patients at high surgical risk [19].

Concerning the endovascular treatment chosen in the case the patient reported, two choices were imposed: either to put a covered stent only at the level of the right iliac artery or a stent covering the aortic bifurcation. Indeed, the main concern was the short distance between the breach and the aortic bifurcation with the significant risk of endoleak. It was decided to put a stent only at the level of the primitive iliac artery but due to a persistent small leakage, a second covered stent was dropped over the aorta, which was well compacted at the origin of the iliac artery. The origin of the hypogastric artery remained free. These precautions allowed us to avoid endo leakage at the proximal stent attachment site. This type of Type 1A endoleak by analogy to aortic stents is exceptionally reported for isolated aneurysms of the iliac arteries. If the leak is significant, this would require the placement of an extension of the stent graft, as in the case of the patient reported below, although a surgical conversion would be required if the endovascular procedure is not possible. Type 2 endoleaks occurring from an arterial branch covered by the stent graft, in this case the internal iliac artery, are the most common. Prior embolization of the internal iliac artery is required prior to stent graft delivery. Type 3 and 4 endoleaks are extremely rare. Moderate endoleaks detected by a scanner should be monitored regularly [20]. The evolution of the cases reported in the literature is characterized by the disappearance of physical signs of heart failure after closure of the shunt as in the patient reported [21]. Furthermore, endovascular treatment is still associated with a low mortality and bleeding rate compared to open surgery.

The placement of covered stents was carried out in about ten patients and the majority of them had an arteriovenous fistula [9-15].

\section{CONCLUSION}

Vascular complications of lumbar disc surgery are rare but are severe. This is reflected in the mortality rates reported in the literature. Risk of the operation must be kept in mind by all surgeons performing those kinds of disc surgery.

Endovascular treatment is indicated for the treatment of arteriovenous fistulas and is increasingly being used even for hemorrhagic forms with hemodynamic stability if an angiography room is available urgently.

\section{REFERENCE}

1. Mixter WJ, Barr JS. Rupture of the intervertebral disc with involvement of the spinal canal. New England Journal of Medicine. 1934 Aug 2;211(5):210-5.

2. Sicard A. Les sciatiques Chirurgie du rachis Paris: Masson et Cie, 1959;232-272.

3. Jarstfer BS, Rich NM. The challenge of arteriovenous fistula formation following disk surgery: a collective review. The Journal of trauma. 1976 Sep;16(9):726-33.

4. Wildförster U. Intraoperative komplikationenwährendlumbaler Bandscheibenoperationen. Kooperative Studie der arbeitsgemeinschaft Wirbelsäule der deutschen Gesellschaftfür Neurochirurgie Neurochirurgia (Stuttg.) 1991;34:862-864

5. Papadoulas S, Konstantinou D, Kourea HP, Kritikos N, Haftouras N, Tsolakis JA. Vascular injury complicating lumbar disc surgery. A systematic review. European Journal of Vascular and Endovascular Surgery. 2002 Sep 1;24(3):18995.

6. Mercier P, Donnez MC, Papon X, Pillet JC, PascoPapon A. Accidents vasculaires au cours de la chirurgie de la hernie discale lombaire: A propos de 3 cas personnels et de 37 cas colligés dans une enquête nationale. Neuro-chirurgie (Paris). 1996;42(4-5):202-8.

7. HoHF RP. 3 Arterial Injuries Occurring During Orthopaedic Operations. Clinical Orthopaedics and Related Research (1976-2007). 1963 Jan $1 ; 28: 21-37$

8. Szolar DH, Preidler KW, Steiner H, Riepl T, Flaschka G, Stiskal M, Moelleken S, Norman D. Vascular complications in lumbar disk surgery: report of four cases. Neuroradiology. 1996 Aug 1;38(6):521-5.

9. Lee KH, Park JH, Chung JW, Han JK, Shin SJ, Kang HS. Vascular complications in lumbar spinal surgery: percutaneous endovascular treatment. Cardiovascular and interventional radiology. 2000 Jan 1;23(1):65-9.

10. Glass BA, Ilgenfritz HC. Arteriovenous fistula secondary to operation for ruptured intervertebral disc. Annals of surgery. $1954 \mathrm{Jul} ; 140(1): 122-127$.

11. Mack JR. Major vascular injuries incident to intervertebral disk surgery. The American surgeon. 1956 Aug;22(8):752-763.

12. Mccarter DA, Johnstone RD, McInnes GC, Reid DB, Pollock JG. Iliac arteriovenous fistula following lumbar disc surgery treated by percutaneous endoluminal stent grafting. British journal of surgery. 1996;83(6):796-7.

13. Ventura M, Rivellini C, Saracino G, Mastromarino A. Endovascular treatment of a postlaminectomy arteriovenous fistula: a case report. Journal of Cardiovascular Surgery. 2002 Aug 1;43(4):523526. 
14. Hong SJ, Oh JH, Yoon Y. Percutaneous endovascular stent-graft for iliac pseudoaneurysm following lumbar discectomy. Cardiovascular and interventional radiology. 2000 Nov 1;23(6):475-7.

15. Canaud L, Hireche K, Joyeux F, D’Annoville T, Berthet JP, Marty-Ané C, Alric P. Endovascular repair of aorto-iliac artery injuries after lumbarspine surgery. European Journal of Vascular and Endovascular Surgery. 2011 Aug 1;42(2):167-71.

16. Wang EA, Lee MH, Wang MC, Lee HY. Iatrogenic left iliac-caval fistula: Imaging and endovascular treatment. American Journal of Roentgenology. 2004 Oct;183(4):1032-4.

17. Beecher S, Alawy M, Elbakar A, Tubassam M. Incidental discovery of a long standing arteriovenous fistula after thrombectomy for acute lower limb ischaemia. International journal of surgery case reports. 2014 Jan 1;5(12):1031-4.

18. Jeuriëns-van de Ven SA, van der Velden AP, Kool LJ, van der Vliet JA, Berger P. Persisting iliacocaval fistula after EVAR maintained by a type II endoleak. Annals of vascular surgery. 2011 Nov 1;25(8):1142-e7.

19. Jarmoune YK, Benhaourech S, Allouch M, Noureddine M, Habbal R. Cardiac consequence of misdiagnosed vascular complication of spinal lumbar surgery: 6 years of diagnosis delay. Journal of cardiology cases. 2016 Jan 1;13(1):6-8.

20. Ben HJ, Maalej A, Lazzez K, Jemal H, Karray S, Ben KM. Endovascular repair of iliocaval arteriovenous fistula complicating lumbar disc surgery. Journal des maladies vasculaires. 2016 May;41(3):205-9.

21. De LM, Arru L, Verbeeck N, Pillet JC. Thrombosis of an aorto-iliac stent graft used for treating an iliocaval arteriovenous fistula following lumbar disc surgery. Journal des maladies vasculaires. $2013 \mathrm{Jul} ; 38(4): 271-5$.

22. Stehr, Schnitzbauer, Steinbauer, Töpel, Pfister, Schlitt, Kasprzak. Early experience shows rapid shrinking of abdominal aortic aneurysms after endovascular treatment with Anaconda ${ }^{\circledR}$ device. Vasa. 2007 Aug 1;36(3):199-204. 